\title{
Prefrontal-hippocampal theta coherence, sharp wave ripples, and bursts of cortical unit activity underlie choices and encoding in the radial arm maze
}

Maxym V Myroshnychenko ${ }^{1 *}$, Christopher C Lapish $^{2}$

From 24th Annual Computational Neuroscience Meeting: CNS*2015

Prague, Czech Republic. 18-23 July 2015

The radial arm maze (RAM) is a foraging task that is often used to assess executive function guided decisionmaking [1-3]. Optimal foraging strategies on this task require the integration of executive and memory systems, which include retrospective and prospective codes. To explore the neural basis of decision-making during RAM performance, the current study acquired multielectrode single-unit and local field potential (LFP)

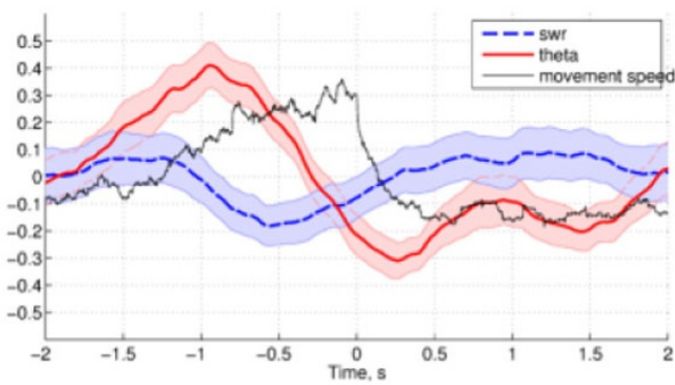

(A)

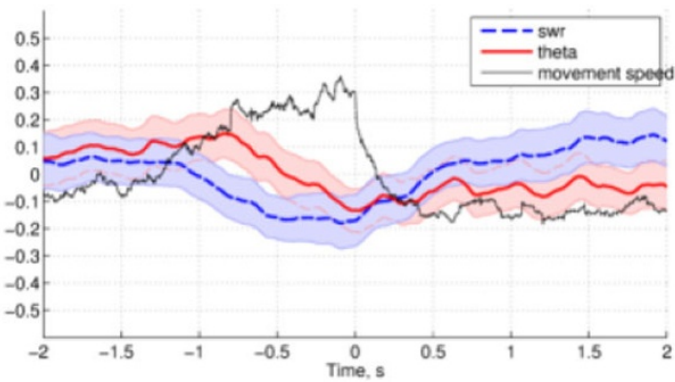

(C)

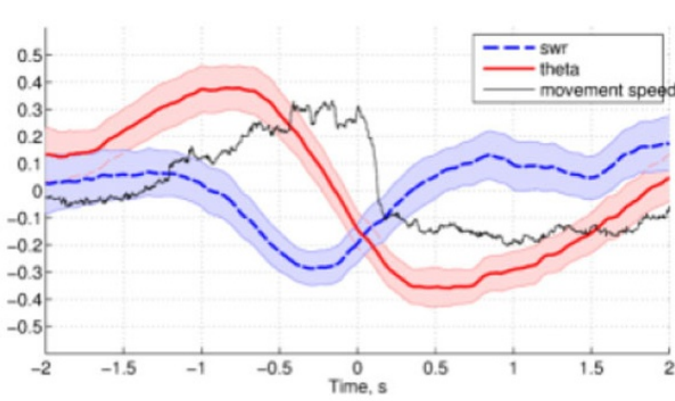

(B)

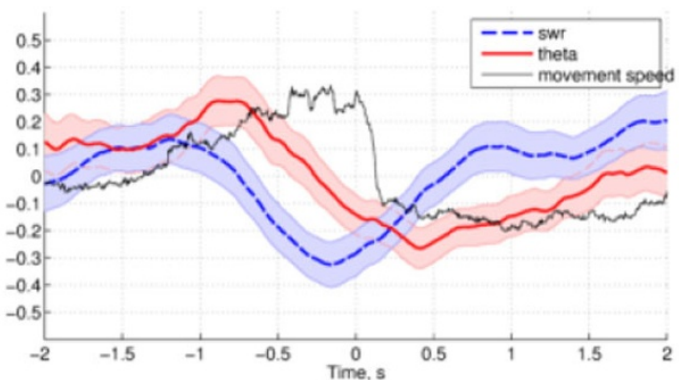

(D)

Figure 1 Average hippocampal and prefrontal theta and SWR power centered on reward acquisition. During test choices (B, D), PFC (D) activity resembles that in $\mathrm{HC}$ (B). On the other hand, during training (A, C), HC (A) shows the pattern of activity associated with reward sites, and PFC (C) does not. Shaded regions, 95\% confidence intervals

\footnotetext{
* Correspondence: mmyros@gmail.com

'Program in Neuroscience, Indiana University, Bloomington, IN 47401, USA
}

Full list of author information is available at the end of the article 
recordings simultaneously in hippocampus $(\mathrm{HC})$ and anterior cingulate (ACC). Initially, rats were presented with four of the eight total maze arms open at once ("training phase"), and the rest of the arms were opened up after the subjects collected the rewards and a oneminute delay was completed ("test phase"). Any arm reentries were counted as errors, and only trials with one test phase error or less were used in the analysis. ACC unit firing was elevated at choice points and reduced at reward points. Moreover, both ACC and the HC showed elevated theta power shortly prior to the reward point and sharp wave ripples shortly after reward acquisition on correct choices only, which is consistent with findings in other choice tasks $[4,5]$. These observations held during test phase (Figure 1, right panels) and were disrupted during the training phase in ACC, but not the $\mathrm{HC}$ (Figure 1, left panels). It has been suggested that HC sharp wave ripples contain episodes of replay of visited locations and theta of locations ahead of the animal $[4,5]$ - information necessary for decision-making using both prospective and retrospective codes. Theta and ripples are present in the $\mathrm{HC}$ during both training and test phases, consistent with lesion evidence that hippocampus is necessary for both prospective and retrospective strategies [1]. In ACC, theta and ripples are only present during test phase and not during training phase, which is in line the evidence showing that prefrontal cortex is only necessary for prospective coding [1]. These task phase-dependent observations may help explain how $\mathrm{HC}$ and ACC networks integrate information related to prospective and retrospective codes.

\footnotetext{
Authors' details

${ }^{1}$ Program in Neuroscience, Indiana University, Bloomington, IN 47401, USA.

${ }^{2}$ Addiction Neuroscience Program, Indiana University-Purdue University,

Indianapolis, IN 46202, USA.
}

Published: 18 December 2015

\section{References}

1. Cook R, Brown M, Riley M: Flexible memory processing by rats: Use of prospective and retrospective information in the radial maze. $J$ ExperPsych 1985, 11(3):453-69.

2. Lapish CC, Durstewitz D, Chandler $\sqcup$, Seamans JK: Successful choice behavior is associated with distinct and coherent network states in anterior cingulate cortex. PNAS 2008, 105(33):11963-8.

3. Zhou W, Hohmann AG, Crystal JD: Rats answer an unexpected question after incidental encoding. Current biology 2012, 22(12):1149-53.

4. Benchenane K, Peyrache A, Khamassi M, Tierney PL, Gioanni Y, Battaglia FP, Wiener SI: Coherent theta oscillations and reorganization of spike timing. Neuron 2010, 66(6):921-36.

5. Jadhav SP, Kemere C, German PW, Frank LM: Awake hippocampal sharpwave ripples support spatial memory. Science 2012, 336(6087):, 1454-8.

doi:10.1186/1471-2202-16-S1-P139

Cite this article as: Myroshnychenko and Lapish: Prefrontal-hippocampal theta coherence, sharp wave ripples, and bursts of cortical unit activity underlie choices and encoding in the radial arm maze. BMC Neuroscience 2015 16(Suppl 1):P139.

\section{Submit your next manuscript to BioMed Central and take full advantage of:}

- Convenient online submission

- Thorough peer review

- No space constraints or color figure charges

- Immediate publication on acceptance

- Inclusion in PubMed, CAS, Scopus and Google Scholar

- Research which is freely available for redistribution 